\title{
Effect of chronic stress on implant osseointegration into rat's mandible ${ }^{1}$
}

\author{
Carlos Rodrigo Barros de SiqueiraI, Tereza Aparecida Delle Vedove Semenoff II, Vinícius Canavarros Palma ${ }^{\mathrm{III}}$, Álvaro Henrique

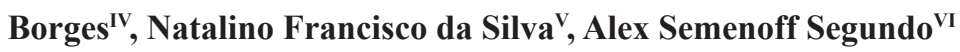

DOI: http://dx.doi.org/10.1590/S0102-865020150090000003

${ }^{\mathrm{I}} \mathrm{MsC}$, Postgraduate Program in Integrated Dentistry Science, Faculty of Dentistry, Universidade de Cuiabá (UNIC), Cuiaba-MT, Brazil. Acquisition, analysis and interpretation of data; technical procedures; histomorphometric examinations.

IIPhD, Associate Professor, Postgraduate Program in Integrated Dentistry Science, Faculty of Dentistry, UNIC, Cuiaba-MT, Brazil. Conception, design, acquisition and interpretation of data; statistical analysis; manuscript writing.

IIIPhD, Associate Professor, Associação Brasileira de Odontologia (ABO), Cuiaba-MT, Brazil. Histopathological examinations, manuscript preparation and writing, critical revision.

${ }^{\text {IV }} \mathrm{PhD}$, Associate Professor, Postgraduate Program in Integrated Dentistry Science, Faculty of Dentistry, UNIC, Cuiaba-MT, Brazil. Manuscript preparation and writing, critical revision.

${ }^{\mathrm{v}}$ Fellow Master degree, Postgraduate Program in Integrated Dentistry Science, Faculty of Dentistry, UNIC, Cuiaba-MT, Brazil. Interpretation of data, statistical analysis.

${ }^{{ }^{V}} \mathrm{PhD}$, Associate Professor, Postgraduate Program in Integrated Dentistry Science, Faculty of Dentistry, UNIC, Cuiaba-MT, Brazil. Conception and design of the study, interpretation of data, statistical analysis, manuscript preparation, critical revision, final approval.

\section{ABSTRACT}

PURPOSE: To compare chronic physical stressed with normal tense animals regarding implant osseointegration in the rat mandible.

METHODS: Thirty six Wistar rats were anesthesiaded and blunt instruments were used to expose and empty their alveolar inferior nerve. One implant $(2.2 \times 4 \mathrm{~mm})$ was installed into the mandibular canal. Following 72 hours, all rats were equally divided in: Control Group analyzed in 18 days (CG18); Control Group analyzed in 33 days (CG33); Stressed Group with stress during 18 days (SG18) and Stressed Group with stress during 33 days (SG33) - The animals from Stressed Groups (CG 18 and CG33) were placed individually in plastic pipes (PVC) during 12 hours daily to physical restraint. Histomorphometric analysis included bone-implant-contact (BIC) and bone area (BA).

RESULTS: In relation to BIC - CG18 (49.8+20.3); SG18 (29.0+16.5) - and BA - CG18 (50.13+21.2); SG18 (23.8+7.8)-, there was a bone repair delayed in SG18 when compared with CG18 ( $<<0.05)$. After 33 days, BIC - CG33 (59.6+26.8); SG33 (49.52+17.3)- and BA - CG33 (41.90+17.4); SG33 (43.91+14.7)- showed no difference between groups ( $>0.05)$.

CONCLUSION: Chronic physical stress interfere with the initial stage of osseointegration in the rat mandible, but not the final process. Key words: Osseointegration. Stress, Physiological. Dental Implants, Rats. 


\section{Introduction}

The scientific community states that stress is one of the major risk factors contributing to the onset of disease ${ }^{1}$. Currently, this condition significantly affects a large portion of the population, irrespective of age, gender, or social class ${ }^{2}$. Chronic stress is related to physical ${ }^{3}$ and emotional ${ }^{4}$ disease. One of the most studied cases related to the etiopathology of stress in dentistry is that of experimental models involving the periodontium of rats ${ }^{5}$.

Dental implants have evolved considerably and include immediate-implantation techniques. However, certain components, such as the implant surface, bone quality, patient habits (such as smoking) and diabetes mellitus ${ }^{6}$ can affect the success of osseointegration? ${ }^{7}$.

The deleterious effects of chronic stress during the early stages of tissue repair are well known ${ }^{8}$. Therefore, the present study aimed to elucidate the process at two stages of osseointegration, one at 18 days, halfway through the cycle of alveolar bone formation in rats 9 , and the other at 33 days, in newly formed bone ${ }^{10}$. The purpose of this investigation was to compare dental implant osseointegration into the mandible of rats submitted to the effect of chronic stress with that in the mandible of rats not submitted to such stress.

\section{Methods}

The experiment was approved by the Ethics Committee for Animal Experimentation (CEEA), Universidade Estadual de of Saão Paulo State Un, iversity under protocol number 77/05.

For this study, 36 Wistar male rats weighing approximately $400 \mathrm{~g}$ each were selected. The animals originated from the animal house of the School of Dentistry, Universidade de Cuiabá (UNIC). Before the experiments, all animals were subjected to an adaptation period and were put in housing cages that were made of plastic and sterilized shredded paper on the floor.

The feed consisted of standard rat chow and water, both ad libitum, throughout the study period. The animals were subjected to a 12-hour light/dark cycle (automated) and controlled temperature and humidity of approximately $24^{\circ} \mathrm{C}$ and $60 \%$, respectively.

All procedures in this phase of the experiment were performed under general anesthesia by means of intramuscular injection of a combination of $0.1 \mathrm{~mL}$ of ketamine hydrochloride and $0.05 \mathrm{~mL}$ of xylazine hydrochloride for each $100 \mathrm{~g}$ of body weight.
The surgical protocol followed the conventional techniques established for placing dental implants with the least possible trauma. After shaving and skin disinfection with $2 \%$ chlorhexidine (Riohex, São José do Rio Preto-SP, Brasil), a 3-cm incision was made on the lateral skin surface of the mandibular body using No. 28 and No. 15 scalpel blades (Swann-MortonSheffield, South Yorkshire, England).

This process was followed by plane-by-plane dissection until the mental foramen and neurovascular bundle were located. The mandibular canal was subsequently emptied, and a cavity was prepared in the canal lumen with spear drills, followed by a 2.0$\mathrm{mm}$ twist drill (both from the Neodent ${ }^{\circledR}$ surgical kit, $5 \mathrm{~mm}$ long, Curitiba-PR, Brasil), under profuse irrigation with $0.9 \%$ sterile saline throughout the procedure. To produce these perforations, drills adapted to a $\mathrm{Kavo}^{\circledR}$ reductor (Kavo do Brasil, Joinvile-PR, Brasil) contra-angle 20:1 and connected to an NSK $^{\circledR}$ electric motor at 1,200 rpm $\left(\mathrm{NSK}^{\circledR}\right.$, Tochigi, Japan) were used.

The implant Neodent ${ }^{\circledR}$, surface treated by subtraction acid), was manually inserted using a 1.2-mm digital key (Figure 1) for the placement of implants with a 2.2-mm diameter and a 4-mm length. The implants were completely inserted into the bone tissue (Figure 2). Soon after each surgery, a single dose of intramuscular benzathine penicillin $G$ (Pentabiótico Veterinário, Pequeno Porte, Fort Dodge ${ }^{\circledR}$, Campinas-SP, Brasil) was administered (20.000 U/kg intra-muscular [IM]), which was prepared and adjusted to the weight of each animal. The rats were monitored daily during the postoperative period; and intramuscular dipyrone sodium $2.5 \mathrm{mg} / 100 \mathrm{~g}$ were proceeding after surgical procedures.

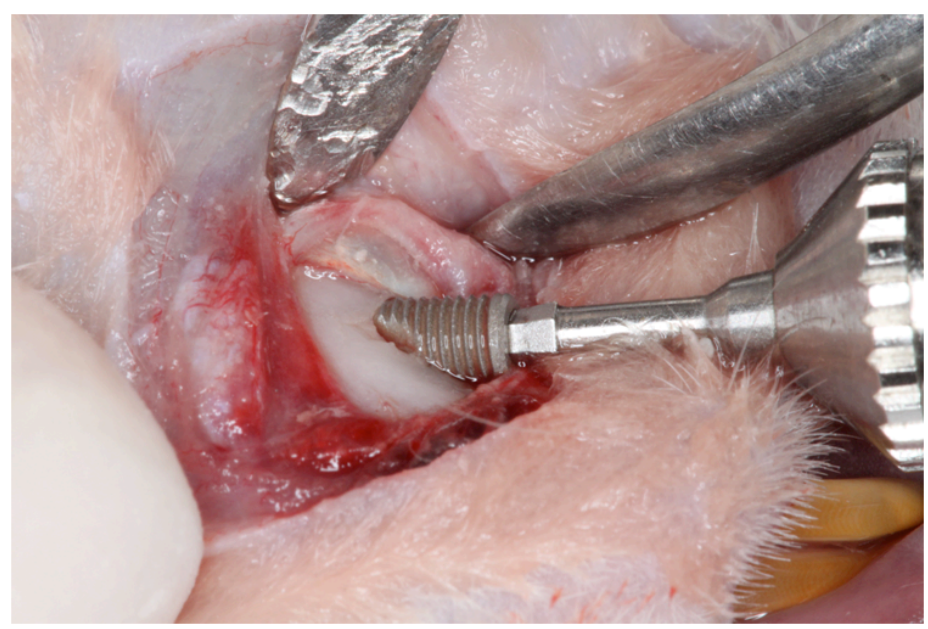

FIGURE 1 - Figure demonstrative of implant with a $2.2 \mathrm{~mm}$ diameter and a $4 \mathrm{~mm}$ length being manually inserted in rat's mandibular canal using a $1.2 \mathrm{~mm}$ digital key. 
Following 72 hours, the 36 rats were divided in four groups: Control Group to be analyzed in 18 days (CG18 - n=9), Control Group to be analyzed in 33 days (CG33 - n=9), Stressed Group with application of 12 hour/day stressing, during 18 days (SG18 $-n=9)$ and Stressed Group with application of 12 hour/day stressing, during 33 days (SG33 - n=9). All groups received water and chow ad libitum.

Animals in the stress group (SG-18 and SG-33) were subjected to chronic stress conditions for 12 hours per day, after a 3-day period of postoperative recovery following the implantation.

The stressor agent used was immobilization. The animals were placed in PVC tubes (Amanco - Mexichem Brasil, São Paulo, SP, Brasil) compatible with their size, which were subsequently sealed with a perforated lid so that the animals could breathe. This procedure lasted 12 hours each day ${ }^{11}$. Both groups underwent this 12-hour period without access to water or feed.

Eighteen days postoperatively, nine rats in SG-18 and nine rats in CG-18 were euthanized by an anesthetic overdose. Thirty-three days postoperatively, the other animals (SG-33 and CG-33) were euthanized following the same procedure.

Prior to euthanasia, which was performed by an anesthetic overdose, the final weight of each animal was measured. Then, using a $10-\mathrm{ml}$ syringe with a $25 \times 7$ needle, a $7-\mathrm{ml}$ blood sample was collected by cardiac puncture without anticoagulant to measure cortisol levels. The cortisol levels for each animal were measured by the electrochemiluminescence method using the Roche $\mathbb{R}$ Cobas E - 411 analyzer (Roche ${ }^{\circledR}$, Basel, AG, Switzerland). After collection of the blood, the mandibles were stored in a container with $10 \%$ formalin.

After histological processing, the polymerized resin blocks containing the specimens were sectioned along the implant axis using the Exakt $^{\circledR}$ System (Exakt Apparatebau, Nordestedt, Hamburg, Germany). The exposed surface of the section had an approximate thickness of $70 \mu \mathrm{m}$ and was subsequently stained with $1 \%$ toluidine blue. A histometric analysis was performed using a Leica DMLB Microscope (Leica Microsystem, Wetzlar, GmbH, Germany) and an LAS4.1.0 analyzer program (Version-Image processing and analysis system, Leica - Wetzlar, GmbH, Germany) for the bone-toimplant contact (BIC) surface and bone area (BA) variables within the limits of the implant threads. Both histometric variables were only evaluated for the first four implant threads, measuring this and subtracting the non-BIC areas of this same region (Figure 3).

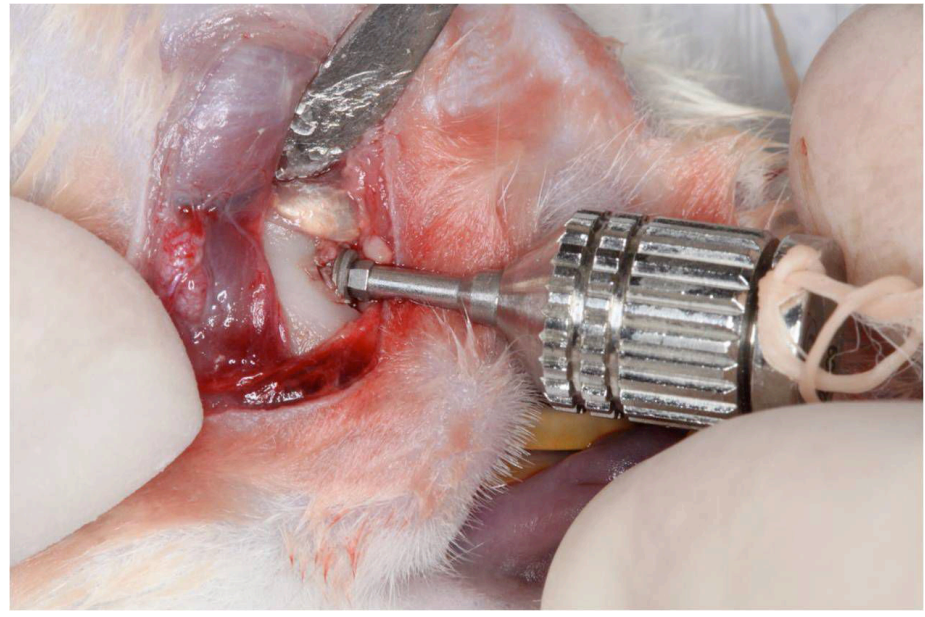

FIGURE 2 - Figure demonstrative of the same implant being completely inserted into the bone tissue.

Initially, the data normality was tested using the Kolmogorov-Smirnov test, which has a Gaussian normal distribution curve. Student's t parametric test for independent samples was selected (IBM SPSS Statistics version 20, Armonk NY, United States). A difference was considered statistically significant if $p<0.05$. For better reliability of the data, the slides were analyzed by an examiner who was blinded to the groups involved in the study. This examiner was trained to understand the histological structures involved.

\section{Results}

During histological processing, eight specimensspecifically, two from each group were lost.

The study results regarding the BIC and BA (Table 1) after 18 days of stress, displayed worsening $(\mathrm{p}<0.05)$ of both evaluated indicators. After 33 days, the BIC and BA exhibited no significant differences ( $>0.05$ ) between the groups (Figure 4$)$.

TABLE 1 - Analysis of histometric measurements used in the study at the 18-day and 33-day experimental time points $(n=7)$.

\begin{tabular}{cccccccc}
\hline \multicolumn{2}{c}{ BIC } & & & \multicolumn{3}{l}{ BA } \\
\cline { 1 - 2 } Groups & Mean & & + & & Groups & Mean & + \\
\cline { 1 - 2 } \cline { 5 - 7 } CG18 & $49.88 *$ & & 20.3 & & CG18 & $50.13 *$ & 21.2 \\
SG18 & $29.00^{*}$ & & 16.5 & & SG18 & $23.82 *$ & 7.8 \\
CG33 & 59.06 & & 26.8 & & CG33 & 41.90 & 17.4 \\
SG33 & 49.52 & 17.3 & & SG33 & 43.91 & 14.7 \\
\hline
\end{tabular}

In columns $(*)$ means statistically significant difference between groups in same experimental time. The data are expressed as percentages; $\mathrm{BIC}$ - bone to implant contact; BA - bone area within the limits of the implant threads; CG - control group; SG - stress group; $(+)$ - standard deviation. (Student's t test for independent samples $-\mathrm{p}<0.05$ ). 


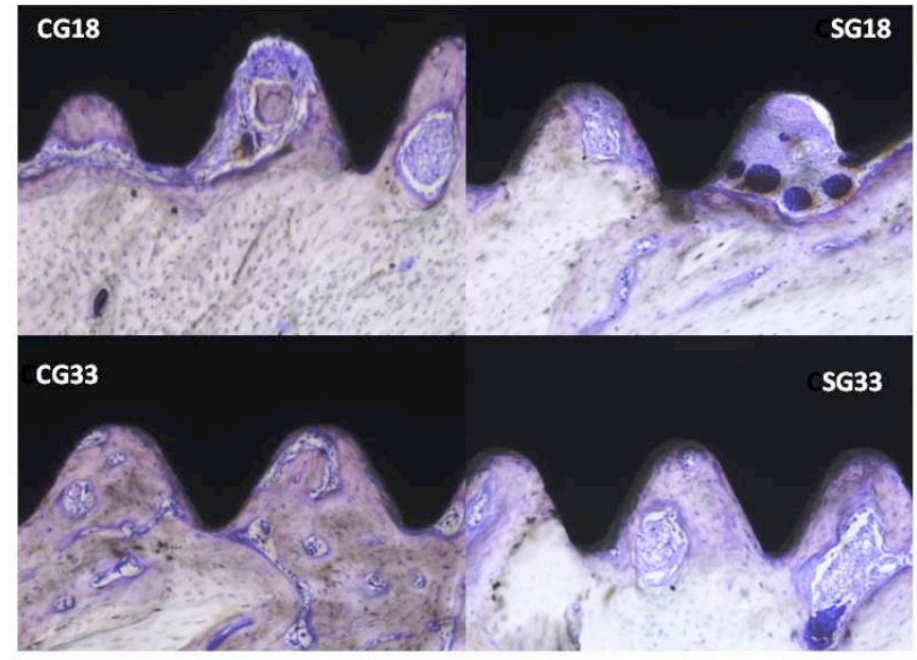

FIGURE 4 - Photograph of histological sections demonstrating differences according to the experimental times. Presence of intense infiltrated inflammatory and neoformation of woven bone in the tissues surrounding of the dental Implant in CG18 - Control Group analyzed in 15 days without stress; The SG - Stress Group with application of 12 hour/ day stressing, during 15 days has late in woven bone and more infiltrated inflammatory surround of tissue neoformation dental implant. CG33 and SG33, The areas intense stains indicate newly formed compact bone. The remodeling activity is marked in areas both adjacent to the pitch of the turns of the dental implant - Original mag. x16.and within the parent bone.

The cortisone measurement results (Table 2) for the experimental period of 18 days and 33 days were significantly higher in the SG than in the CG $(p<0.05)$. Regarding the weight difference of the animals (Table 2), there was no significant difference $(p>0.05)$ between the $\mathrm{SG}$ and the CG at 18 days. However, at 33 days, there was a greater loss of body mass in the $\mathrm{SG}$, with a significant difference $(\mathrm{p}<0.05)$.

TABLE 2 - Cortisol levels $(\mu \mathrm{g} / \mathrm{dl})$ in the bloodstream at 18 and 33 days and weight difference at 18 and 33 days $(n=7)$.

\begin{tabular}{ccccccc}
\hline \multicolumn{2}{c}{ Cortisol levels $(\boldsymbol{\mu g} / \mathrm{dl})$} & \multicolumn{3}{c}{$\begin{array}{c}\text { Weight difference at the end of } \\
\text { the trial }\end{array}$} \\
$\begin{array}{c}\text { Experimental } \\
\text { times }\end{array}$ & Mean & + & \multicolumn{3}{c}{$\begin{array}{c}\text { Experimental } \\
\text { times }\end{array}$} \\
\hline SG 18 & $3.86^{*}$ & 0.82 & & SG 18 & 21.22 & 6.30 \\
CG 18 & $3.58^{*}$ & 0.76 & & CG 18 & 22.66 & 4.97 \\
SG 33 & $5.17^{* *}$ & 1.58 & & SG 33 & $46.33 * * *$ & 8.13 \\
CG 33 & $3.31^{* *}$ & 1.17 & & CG 33 & $56.22 * * *$ & 7.44 \\
\hline
\end{tabular}

*Statistically significant difference $(\mathrm{p}<0.05)$ between the amount of cortisol hormone during the 18 day experimental period for the CG and SG. ** Statistically significant difference $(\mathrm{p}<0.05)$ between the amount of cortisol hormone during the 33 day experimental period for the CG and SG. ${ }^{* * *}$ Statistically significant difference $(\mathrm{p}<0.05)$ for the difference between the initial and final weights at 33-day experimental time points for the CG and SG. CG - control group; SG - stress group; $(+)-$ standard deviation. (Student's $t$ test for independent samples $-\mathrm{p}<0.05$ ).

\section{Discussion}

It was expected that stress would delay the repair after 18 days and after 33 days. However, the results of this paper revealed worsening of the osseointegration process in animals that were subjected to stress at 18 days and no comparative difference in the osseointegrative bone formation at the 33-day experimental period.

Some situations may have contributed to the present findings. It has been established that stress can suppress or stimulate the immune defense, depending on the stressor ${ }^{14}$. Moreover, stress activates the hypothalamic-pituitary-adrenal axis, which causes the release of neuroendocrine hormones, resulting in cortisol secretion by the adrenal cortex ${ }^{15}$, often making the individual susceptible to disease ${ }^{16}$. There is evidence that physical or chemical modulation occurs in the marginal and apical periodontium, leading to a better or worse response to the immuno-inflammatory stimulus of periodontitis induction ${ }^{17}$.

The tissue repair rate is influenced by determinants such as chronic stress and acute stress ${ }^{8}$. The influence of highintensity, chronic stress such as that induced in this study ${ }^{17}$ worsens the healing of still immature tissue, as was the case after the experimental period of 18 days found in this study. Stress, in these conditions may have caused a reduction in the formation of the bone matrix, osteoblasts, and collagen fibers ${ }^{18}$. A determining factor in the bone formation rate is linked to pro-inflammatory interleukins ${ }^{19}$, which exhibit more intense activity during the early stages of the repair process, including the activation of the base formed by fibroblasts, which in turn synthesize collagen, a key element in the formation and organization of the connective tissue of the jaws.

The results of the present study reveal that the group without stress (control group) displayed areas where the inflammatory cellular process was already reduced and that there was bone formation between the implant threads. The test group subjected to the stress trials exhibited a delay in repair process, an increased inflammatory infiltrate, a lower BIC surface area, and a lower BA formed within the limits of the implant threads at 18 days. The results observed at 33 days, there was newly formed bone in both groups, with no significant differences 9 .

The experimental time used in this paper were chosen for fetching, as the described hypothesis, an understanding aboust the effect of chronic stress on the osseointegration in a period in which the bone is still maturation bone (18 days) ${ }^{1,9} 9,1$ and other already mature (33 days $)^{9,12}$ 
In this way, the results observed in the present study suggest that chronic stress did not influence osseointegration at 33 days when compared with the control group. As indicated by the literature, after a repair period of 28 days, pro-inflammatory interleukins such as IL1B and IL6 do not appear to influence the inflammatory stage of repair ${ }^{14,20,21}$.

Another noteworthy issue is that after 33 days of stress, the animals may have adapted to the stress model ${ }^{22,23}$, although the cortisol levels measured suggest the opposite, as the biochemical results presented in this study. Studies using physical restraint for 12 hours as an experimental model to induce stress are not a recent development ${ }^{24,25}$. The cortisol level is widely used in the literature as a varying physiological parameter associated with the presence of stress $^{29}$, and the measurement results in this study show that there is a greater amount of this hormone in the bloodstream in the experimental stress model.

Studies in animals are important in providing information on the pathogenesis and progression of periodontal disease. Unfortunately, despite performing an extensive literature review, we were unable to identify comparative parameters for osseointegration and chronic stress in the main databases. In view of this fact the results of this study may become relevant in future trials in animals or in humans because the influence of stress acting on bone with titanium implants in initial stages of repair is an interesting clinical finding; in actuality, there are cases involving the insertion of dental implants and function immediately, i.e., within the same session the patient leaves the dental clinic with prostheses supported by implants, or just with the implant.Naturally, a well-established model in the literature was sought, which led us to choose a chronic-stress model involving physical restraint for 12 hours ${ }^{11,13,17,26}$. It is currently understood that for successful implant dentistry, certain criteria must be met, including an atraumatic surgical technique, primary stability, implant selection, the quality and quantity of bone ${ }^{27}$, periodic preventive maintenance, and knowledge of the physiological and/ or pathological changes in preexisting conditions ${ }^{28}$. The latter may involve stress.

As has been demonstrated in the results of this study, chronic stress can affect the initial repair process in rat mandible; therefore, it seems plausible that research on human seek to determine whether patients undergoing chronic stress could suffer interference in the initial stages of osseointegration.

Some methodological items are relevant and deserve to be highlighted. The histometric assessment (BIC and BA) adopted is well known and widely used by various research groups ${ }^{30}$. The selection of implants was based on several anthropometric pilot studies in animals. Based on this anatomical knowledge, we sought to establish a surgical technique for assessing the animals' survival and other changes, as necessary. A different approach to that presented in the literature was thus defined. The procedure in this study was performed by the extraoral route, which was followed by emptying the mandibular canal and inserting the implant into the canal lumen. This technique is quite different from other methods used in the oral cavities of rats r,10-12. $^{9}$.

The size of the implants in the literature was $1.15 \mathrm{~mm}$ in diameter and $3 \mathrm{~mm}$ in length ${ }^{9,12}$. When contacted, the manufacturer revealed that implants with the above-cited diameters could not have been subjected to surface treatment. Implants of $2.2 \mathrm{~mm}$ diameter and $4 \mathrm{~mm}$ length were therefore produced. This procedure caused the teeth to make contact with the final third of the implant apex, which led to the formation of soft tissue, but that outcome was not the object of analysis, as a standardized area (distance among four implant threads) was determined for all implants in the middle and cervical third.

Given the above discussion, it is clear that this methodology is still incipient and should be interpreted with caution. However, these findings indicate that the placement of implants in this region is feasible for rat models and, when associated with stress studies, may help to clarify the information gathered through further research.

\section{Conclusion}

Chronic physical stress interfere with the initial stage of osseointegration in the rat mandible, but not the final process.

\section{References}

1. Sacco P, Bucholz KK, Harrington D. Gender differences in stressful life events, social support, perceived stress, and alcohol use among older adults: results from a national survey. Subst Use Misuse. 2014 Mar;49(4):456-65. doi: 10.3109/10826084.2013.846379.

2. Smedt DD, Clays E, Annemans L, Boudrez H, De Sutter J, Doyle F, Jennings C, Kotseva K, Pająk A, Pardaens S, Prugger C, Wood D, D Bacquer D. The association between self-reported lifestyle changes and health-related quality of life in coronary patients: the EUROASPIRE III survey. Eur J Prev Cardiol. 2014 Jul;21(7):796805. doi: $10.1177 / 2047487312473846$.

3. O'Connor TG, Monk C, Fitelson EM. Practitioner review: maternal mood in pregnancy and child development--implications for child psychology and psychiatry. J Child Psychol Psychiatry. 2014 Feb;55(2):99-111. doi: 10.1111/jcpp.12153.

4. Dyb G, Jensen TK, Nygaard E, Ekeberg O, Diseth TH, Wentzel-Larsen T, Thoresen S. Post-traumatic stress reactions in survivors of the 2011 massacre on Utoya Island, Norway. Br J Psychiatry. 2014 May;204:361-7. doi: 10.1192/bjp.bp.113.133157.

5. Semenoff-Segundo A, Porto AN, Semenoff TA, Cortelli JR, Costa FO, Cortelli SC, Bosco AF. Effects of two chronic stress models on 
ligature-induced periodontitis in Wistar rats. Arch Oral Biol. 2012 Jan;57(1):66-72. doi: 10.1016/j.archoralbio.2011.07.014.

6. Parveen S, Singh SB. Stress and adjustment in diabetes mellitus. Indian J Psychiatry. 1999 Jan;41(1):66-9. PMID: 21455356.

7. Delben JA, Goiato MC, Pellizzer EP, Magro Filho O. Planning for immediate loading of implant-supported prostheses: literature review. J Oral Implantol. 2012 Sep;38 Spec No:504-8. doi: 10.1563/ AAID-JOI-D-10-00188.

8. Takada T, Yoshinari N, Sugiishi S, Kawase H, Yamane T, Noguchi T. Effect of restraint stress on the progression of experimental periodontitis in rats. J Periodontol. 2004 Feb;75(2):306-15. PMID: 15068120.

9. Fujii N, Kusakari H, Maeda T. A histological study on tissue responses to titanium implantation in rat maxilla: the process of epithelial regeneration and bone reaction. J Periodontol. 1998 Apr;69(4):48595. PMID: 9609380.

10. Haga M, Fujii N, Nozawa-Inoue K, Nomura S, Oda K, Uoshima K, Maeda T. Detailed process of bone remodeling after achievement of osseointegration in a rat implantation model. Anat Rec (Hoboken). 2009 Jan;292(1):38-47. doi: 10.1002/ar.20748.

121. Semenoff-Segundo A, Semenoff TA, Borges AH, Pedro FL, Sakai VT. Methodological model of chronic stress associated with ligature-induced periodontitis in rats: a radiographic study. Braz Oral Res. 2010 Oct-Dec;24(4):455-9. PMID: 21180968 [PubMed indexed for MEDLINE].

12. Shirakura M, Fujii N, Ohnishi H, Taguchi Y, Ohshima H, Nomura S, Maeda T. Tissue response to titanium implantation in the rat maxilla, with special reference to the effects of surface conditions on bone formation. Clin Oral Implants Res. 2003 Dec;14(6):687-96. PMID: 15015943

13. Peruzzo DC, Benatti BB, Antunes IB, Andersen ML, Sallum EA, Casati MZ, Nociti FH, Nogueira-Filho GR. Chronic stress may modulate periodontal disease: a study in rats. J Periodontol. 2008 Apr;79(4):697-704. doi: 10.1902/jop.2008.070369.

14. Gomes EP, Aguiar JC, Fonseca-Silva T, Dias LC, Moura-Boas KP, Roy A, Velloso NA, Rodrigues-Neto JF, De-Paula AM, Guimarães AL. Diazepam reverses the alveolar bone loss and hippocampal interleukin-1beta and interleukin- 6 enhanced by conditioned fear stress in ligature-induced periodontal disease in rats. J Periodontal Res. 2013 Apr;48(2):151-8. doi: 10.1111/j.1600-0765.2012.01515.x.

15. Dantzer R, Kelley KW. Stress and immunity: an integrated view of relationships between the brain and the immune system. Life Sci. 1989;44(26):1995-2008. PMID: 2568569.

16. Nakajima K, Hamada N, Takahashi Y, Sasaguri K, Tsukinoki K, Umemoto T, Sato S. Restraint stress enhances alveolar bone loss in an experimental rat model. J Periodontal Res. 2006 Dec;41(6):52734. PMID: 17076777

17. Semenoff-Segundo A, Porto AN, Semenoff TA, Cortelli JR, Costa FO, Cortelli SC, Bosco AF. Effects of two chronic stress models on ligature-induced periodontitis in Wistar rats. Arch Oral Biol. 2012 Jan;57(1):66-72. doi: 10.1016/j.archoralbio.2011.07.014.

18. Johannsen A, Rydmark I, Söder B, Asberg M. Gingival inflammation, increased periodontal pocket depth and elevated interleukin- 6 in gingival crevicular fluid of depressed women on long-term sick leave. J Periodontal Res. 2007 Dec;42(6):546-52. PMID: 17956468.

19. Marucha PT, Kiecolt-Glaser JK, Favagehi M. Mucosal wound healing is impaired by examination stress. Psychosom Med. 1998 MayJun;60(3):362-5. PMID: 9625226.

20. Gaspersic R, Stiblar-Martincic D, Skaleric U. Influence of restraint stress on ligature-induced periodontitis in rat. Eur J Oral Sci. 2002 Apr;110(2):125-9. PMID: 12013555.

21. Breivik T, Thrane PS, Murison R, Gjermo P. Emotional stress effects on immunity, gingivitis and periodontitis. Eur J Oral Sci. 1996 Aug;104(4 (Pt 1):327-34. PMID: 8930578.
22. Segundo AS, Hennemann K, Fontanella VR, Rösing C. The role of psychoneuroimmune interactions in the pathogenesis of ligatureinduced periodontal disease in Wistar rats. J Int Acad Periodontol. 2007 Jan;9(1):26-31. PMID: 17274237.

23. Selye H. Stress and disease. Science. 1955 Oct;122(3171):625-31. PMID: 13255902.

24. Carranza Jr FA, Simes RJ, Cabrine RL. Effect of combined etiologic factors in experimental periodontal lesions. J Periodontal Res Suppl. 1969;(4):33-4. PMID: 4245487.

25. Carranza FA Jr, Simes RJ, Mayo J, Cabrini RL. Histometric evaluation of periodontal bone loss in rats. I. the effect of marginal irritation, systemic irradiation and trauma from occlusion. J Periodontal Res. 1971;6(1):65-72. PMID: 4255157.

26. Porto AN, Semenoff Segundo A, Vedove Semenoff TA, Pedro FM, Borges AH, Cortelli JR, Costa Fde O, Cortelli SC. Effects of forced alcohol intake associated with chronic stress on the severity of periodontitis: an animal model study. Int J Dent. 2012;2012:465698. doi: $10.1155 / 2012 / 465698$.

27. Albrektsson T, Zarb G, Worthington P, Eriksson AR. The longterm efficacy of currently used dental implants: a review and proposed criteria for success. Int J Oral Maxillofac Implants. 1986 Summer;1(1):11-25. PMID: 3527955.

28. Frisch E, Ziebolz D, Rinke S. Long-term results of implantsupported over-denture retained by double crowns: a practicebased retrospective study after minimally 10 years follow-up. Clin Oral Implants Res. 2013 Dec;24(12):1281-7. doi: 10.1111/j.16000501.2012.02568.x.

29. Rivera C, Monsalve F, Suazo I, Becerra J. Stress increases periodontal inflammation. Exp Ther Med. 2012 Nov;4(5):883-888. PMID: 23226743.

30. Correa MG, Gomes Campos ML, César-Neto JB, Casati MZ, Nociti FH, Sallum EA. Histometric evaluation of bone around titanium implants with different surface treatments in rats exposed to cigarette smoke inhalation. Clin Oral Implants Res. 2009 Jun;20(6):588-93. doi: 10.1111/j.1600-0501.2008.01695.x.

\section{Acknowledgement}

To Neodent ${ }^{\circledR}$ for providing the implants used in this study.

\section{Correspondence:}

Alex Semenoff-Segundo

Avenida Manoel José de Arruda, 3.100

78065-900 Cuiabá - MT Brasil

Tel.: (55 65)3623-3009 / 9983-8030

semenoff@uol.com.br

Received: May 8, 2015

Review: July 13, 2015

Accepted: Aug 11, 2015

Conflict of interest: none

Financial source: none

${ }^{1}$ Research performed at Department of Master Program in Integrated Dentistry Science, Universidade de Cuiabá (UNIC), Cuiabá-MT, Brazil. Part of Master degree thesis, Postgraduate Program in Integrated Dentistry Science. Tutor: Alex Semenoff-Segundo. 